\title{
Electrocatalytic Oxidation of Methanol on Nickel Doped Metal- Organic Frameworks MIL-110 Modified Glassy Carbon Electrode in Alkaline Medium
}

Yan Wang ${ }^{1,+}, *$, Chenglian Liu ${ }^{l, \dagger}$, Jiangnan Xiang ${ }^{l}$, Lei Xing ${ }^{2}$, Xiaoyu Ou ${ }^{l}$, Shili Chen ${ }^{1}$, Xiaojun Xue ${ }^{1}$, Feng Y ${ }^{l}$, Ruifeng $\mathrm{Li}^{1}$

${ }^{1}$ College of Chemistry and chemical Engineering, Taiyuan University of Technology, Shanxi, 030024, China

${ }^{2}$ Institute of Green Chemistry and Chemical Technology, Jiangsu University, Zhenjiang, 212013,

China

$\dagger$ These authors contribute equally to this paper.

*E-mail: wangyan@tyut.edu.cn

doi: $10.20964 / 2019.06 .11$

Received: 5 January 2019 / Accepted: 20 February 2019 / Published: 10 May 2019

Nickel doped metal-organic frameworks MIL-110 catalysts were prepared by impregnation method. The as-prepared Ni/MIL-110 catalysts with different Ni content (10 wt.\%, $20 \mathrm{wt} . \%$ and $30 \mathrm{wt} . \%)$ were characterized by XRD, SEM, elemental distribution analysis, $\mathrm{N}_{2}$ adsorption-desorption and TEM. Ni/MIL-110 modified glassy carbon electrodes were employed to investigate the methanol electrooxidation reaction (MOR) in $0.1 \mathrm{M} \mathrm{NaOH}$ by cyclic voltammetry (CV) and chronoamperometry (CA). Ni/MIL-110 shows good electrocatalytic acidity toward MOR and MOR reaction is under diffusion controlled. And the catalytic rate constant is calculated to be $0.96 \times 10^{3} \mathrm{~cm}^{3} \mathrm{~mol}^{-1} \mathrm{~s}^{-1}$ by CA analysis.

Keywords:Alkaline medium, Glassy Carbon Electrode, Metal-organic Frameworks, Methanol Electrooxidation

\section{FULL TEXT}

(C) 2019 The Authors. Published by ESG (www.electrochemsci.org). This article is an open access article distributed under the terms and conditions of the Creative Commons Attribution license (http://creativecommons.org/licenses/by/4.0/). 